\title{
Real-time ionospheric N(h) profile updating over Europe using IRI-2000 model
}

\author{
D. Buresova ${ }^{1}$, Lj. R. Cander ${ }^{2}$, A. Vernon ${ }^{2}$, and B. Zolesi ${ }^{3}$ \\ ${ }^{1}$ Institute of Atmospheric Physics, Czech Republic \\ ${ }^{2}$ Rutherford Appleton Laboratory, United Kingdom \\ ${ }^{3}$ Istituto Nazionale di Geofisica e Vulcanologia, Italy
}

\begin{abstract}
In this paper a method for real-time updating of ionospheric electron density profile, $\mathrm{N}(\mathrm{h})$, over Europe using an ionospheric model and real-time measurements at ionosonde locations is presented. The $\mathrm{N}(\mathrm{h})$ profile update over European area has been simulated with the IRI-2000 ionospheric model and real-time $\mathrm{N}(\mathrm{h})$ profiles obtained from the EU COST271 Action Space Weather Database. Preliminary findings are shown for the geomagnetically quiet day on 4 May 2003 and disturbed day on 24 May 2002. Results are discussed in the context of real-time $\mathrm{N}(\mathrm{h})$ profile updating capabilities and effectiveness.
\end{abstract}

\section{Introduction}

The International Reference Ionosphere-IRI (Bilitza, 2001) is one of the most widely used empirical models. Among others, it describes the median values of electron density as a function of height for a given location, time and sunspot number. The IRI model is being refined following the annual IRI workshops and currently contains the foF 2 storm model (Araujo-Pradere, et al., 2002a, b; Bilitza, 2003). This paper presents the comparative study of the electron density maps generated using a method for real-time ionospheric N(h) profiles updating and those obtained by the IRI-2000 model over Europe. The intent is to provide a possibility for a further IRI model improvement. Therefore, in this study the N(h) profile simulation has been performed by using online information available at the IRI web side http://nssdc.gsfc.nasa. gov/space/model/models/iri.html and at the COST271 Space Weather Database web side http://www.wdc.rl.ac.uk/cgi-bin/ digisondes/cost_database.pl. (Zolesi and Cander, 2003). A few other stations operating in non real-time mode in Europe are used to provide additional IRI-2000 N(h) profiles required for mapping $\mathrm{NmF} 2, \mathrm{hmF} 2$ and electron density at

Correspondence to: D. Buresova

(buresd@ufa.cas.cz) the F1-region heights over Europe. Ionospheric stations involved in this study are listed in Table 1.

Initial comparison of the measured and IRI generated N(h) profiles has been done for two stations: Pruhonice and Ebre. Some of the results obtained for the period of 14-21 February 1998 are given in Fig. 1. In this period the first three days were geomagnetically quiet, followed by the storm on 18 February and then a long lasting recovery phase. At Pruhonice station it can be seen that: (1) there is a good agreement between IRI model (red line) and $\mathrm{NmF} 2$ measured data (black line) for the whole period; (2) in general, there is no agreement between IRI model and electron density measured values at F1-region height. It is particularly true during the main phase of the geomagnetic storm and at the height of $180-190 \mathrm{~km}$ in the F1-region. The same is valid for the similar comparison made for Ebre station also shown in Fig. 1.

Examples at Fig. 1 demonstrate that it is possible to use IRI model for mapping ionospheric electron density at the certain heights over European region, as at hmF2 and at fixed F1-region heights, during quiet ionospheric conditions. During disturbed conditions IRI still cannot produce appropriate values mainly at F1 heights and therefore reasonably accurate $\mathrm{N}(\mathrm{h})$ profile as a whole. This is the main reason to introduce a method of the ionospheric 3D modelling by real-time $\mathrm{N}(\mathrm{h})$ profile updating with measured data.

\section{Real-time N(h) updating results}

Figure 2 shows the 4 May 2003 geomagnetically quiet study case at 11:00 UT. Left panel contains maps of electron density measured data at $\mathrm{hmF} 2$ and $190 \mathrm{~km}$, while on the right panel maps are produced by IRI model using the same locations of five stations. It can be seen that $\mathrm{NmF} 2$ map over Europe obtained by measured values from selected stations was slightly different than IRI map itself. In the case of F1region electron density maps it is clearly evident the significant discrepancy between maps of measured electron density data and IRI map. The IRI model underestimated electron 
Table 1. List of contributing vertical incidence ionospheric stations.

\begin{tabular}{cccc}
\hline VI station & Latitude $\left({ }^{\circ} \mathrm{N}\right)$ & Longitude $\left({ }^{\circ} \mathrm{E}\right)$ & Data available \\
\hline Chilton & 51.5 & -1.3 & Real-time mode \\
Athens & 38.0 & 23.6 & Real-time mode \\
El Arenosillo & 37.1 & -6.8 & Non real-time mode \\
Ebre & 40.8 & 0.5 & Non real-time mode \\
Troms $\varnothing$ & 69.9 & 19.0 & Real-time mode \\
Roma & 41.9 & 12.5 & Real-time mode \\
Juliusruh & 54.6 & 13.4 & Real-time mode \\
Pruhonice & 50.0 & 14.6 & Non real-time mode \\
Warsaw & 52.2 & 21.2 & Non real-time mode \\
Dourbes & 51.2 & 0.46 & Non real-time mode \\
Uppsala & 59.8 & 17.6 & Non real-time mode \\
\hline
\end{tabular}
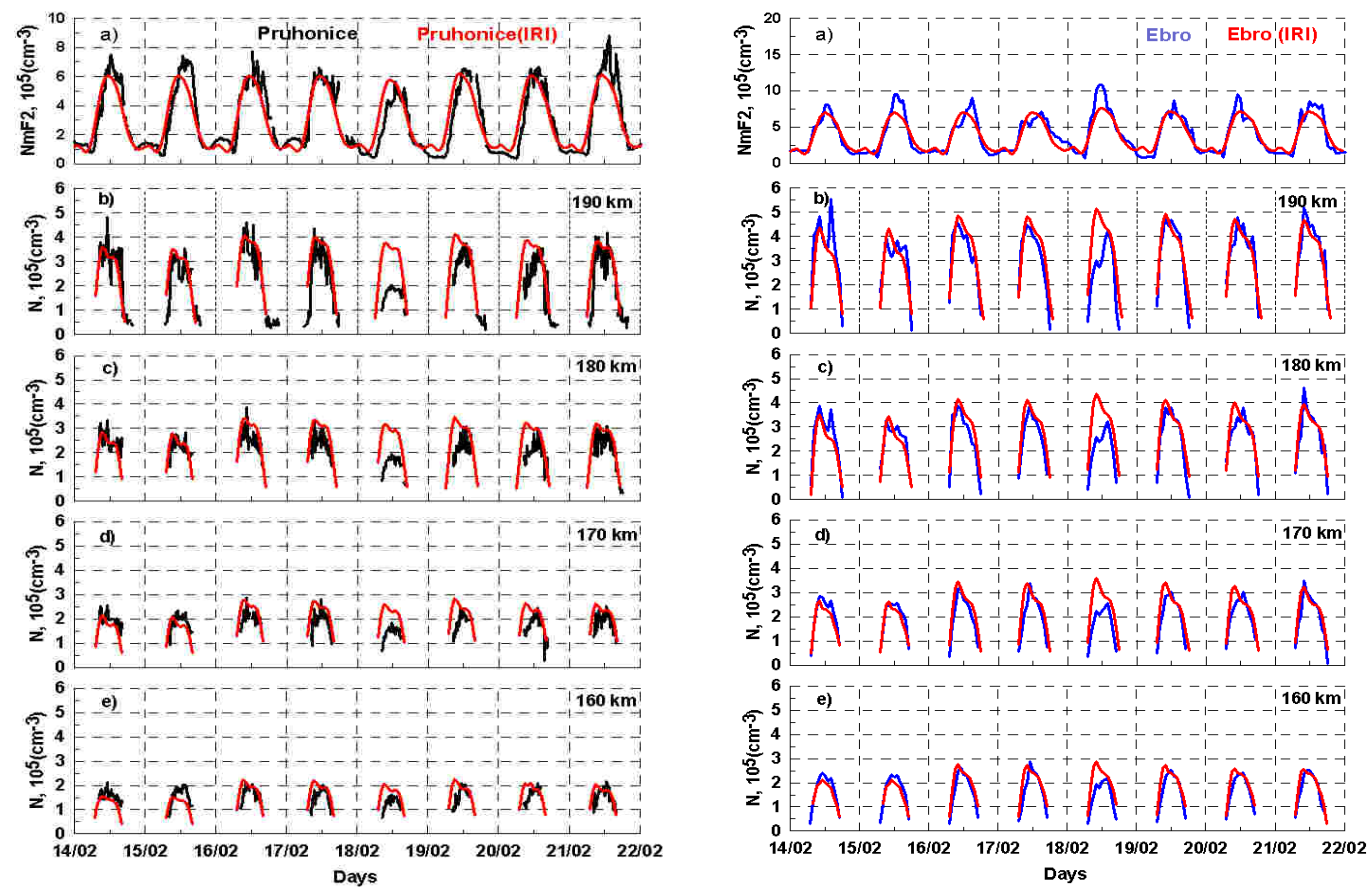

Fig. 1. Daily hourly NmF2 values and electron density values at specific heights obtained at Pruhonice (left panel) and at Ebre (right panel) stations and by IRI model during the period 14-21 February 1998.

density at $190 \mathrm{~km}$ height for all selected stations. To compare quiet and disturb periods in the same way as before, the disturbed day of 24 May 2002 was chosen based on the minimum value of the Dst index of $-108 \mathrm{nT}$ at late evening of the previous day. Figure 3 shows that at 11:00 UT on 24 May 2002 both NmF2 and the F1-region height maps over Europe obtained by measured values are significantly different than corresponding IRI maps. The advantage of using real-time data to update the IRI model values is obvious and most clearly seen at the F1-region height.

For the same days of 4 May 2003 and 24 May 2002 the simulation of an updating ionospheric model has been done by using 5 and 4 stations respectively, which offer the realtime measurements and the IRI N(h) profile values for other stations given in Table 1. Figures 4 and 5 show on the left side the simulated maps and on the right side maps produced with IRI values only for both selected days. Updated NmF2 maps and IRI model itself show relatively good agreement. In contrast to NmF2, updated F1-region maps differ significantly from maps generated using IRI model data. In general, at European middle latitudes the F1-region response to spring-summer time geomagnetic storm is significantly smaller compared to other seasons (Buresova, et al., 2002; Mikhailov and Schlegel, 2003). Consequently, the updated IRI model maps for F1-region are quite similar for both selected quiet and disturbed days. The most important result seen at the Figs. 4 and 5 is that updating IRI model describes the actual ionospheric structure better then the IRI model itself. The quality of the maps will obviously depend on the number of ionospheric stations which can provide the realtime $\mathrm{N}(\mathrm{h})$ profiles. 

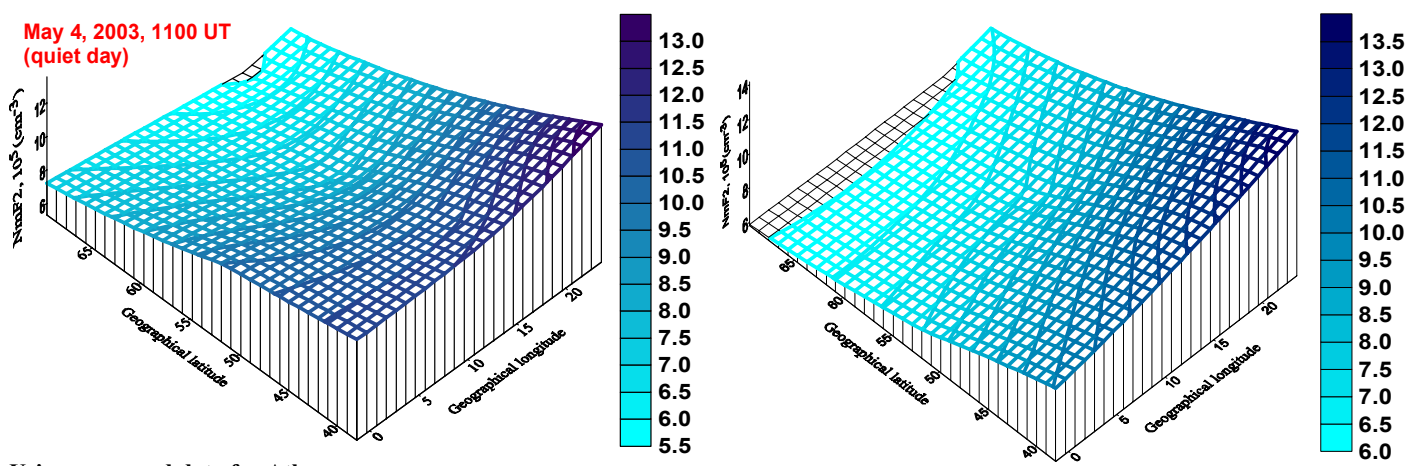

Using measured data for Athens,

Roma, Chilton, Juliusruh and Tromso
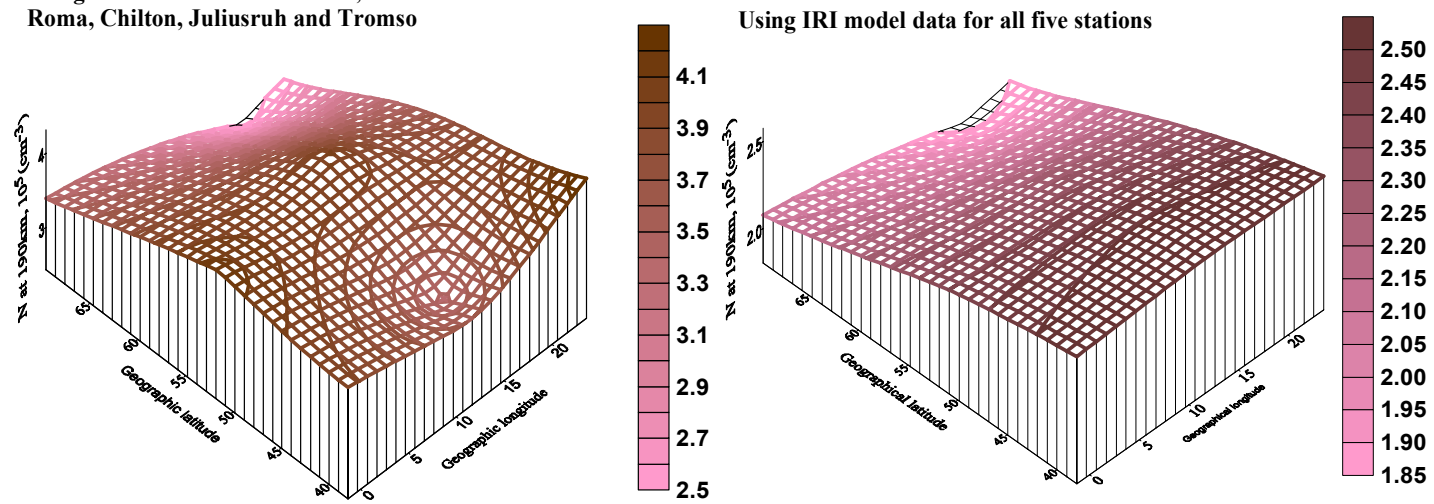

Fig. 2. Maps of the NmF2 and the electron density at $190 \mathrm{~km}$ values generated by measured data (left panel) and IRI data (right panel) on 4 May 2003 at 11:00 UT.
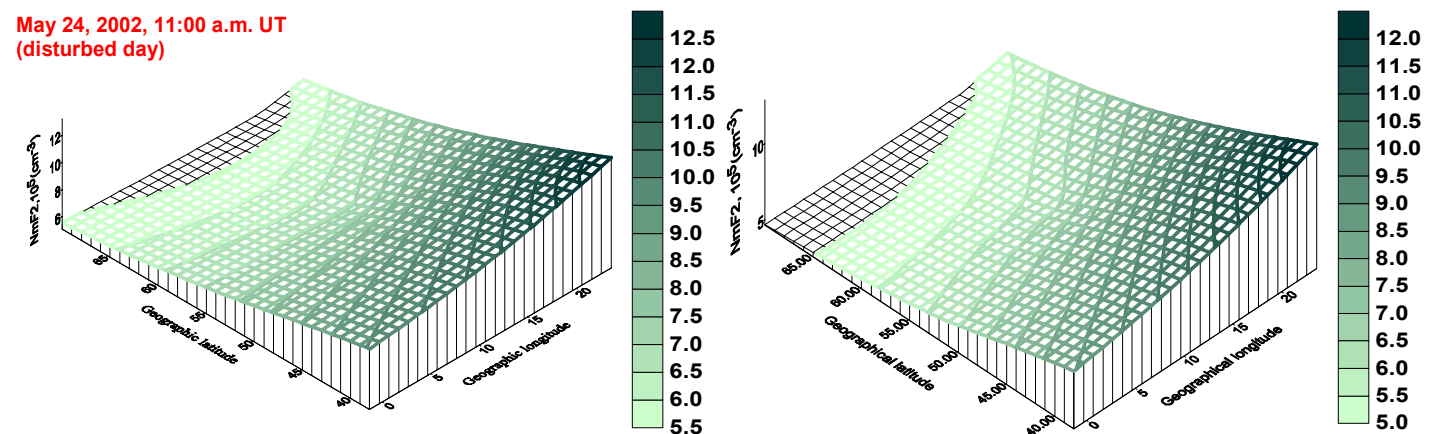

Using measured data for Athens, Chilton, Juliusruh and Tromso
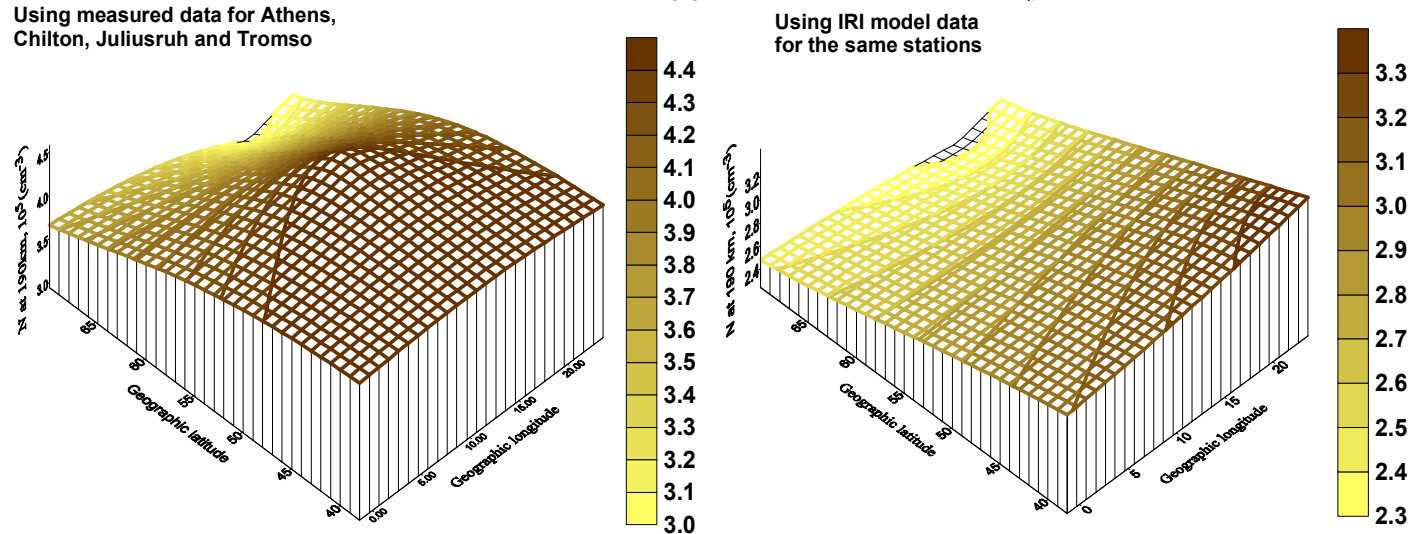

Fig. 3. Maps of the NmF2 and the electron density at $190 \mathrm{~km}$ values generated by measured data (left panel) and IRI data (right panel) on 24 May 2002 at 11:00 UT. 

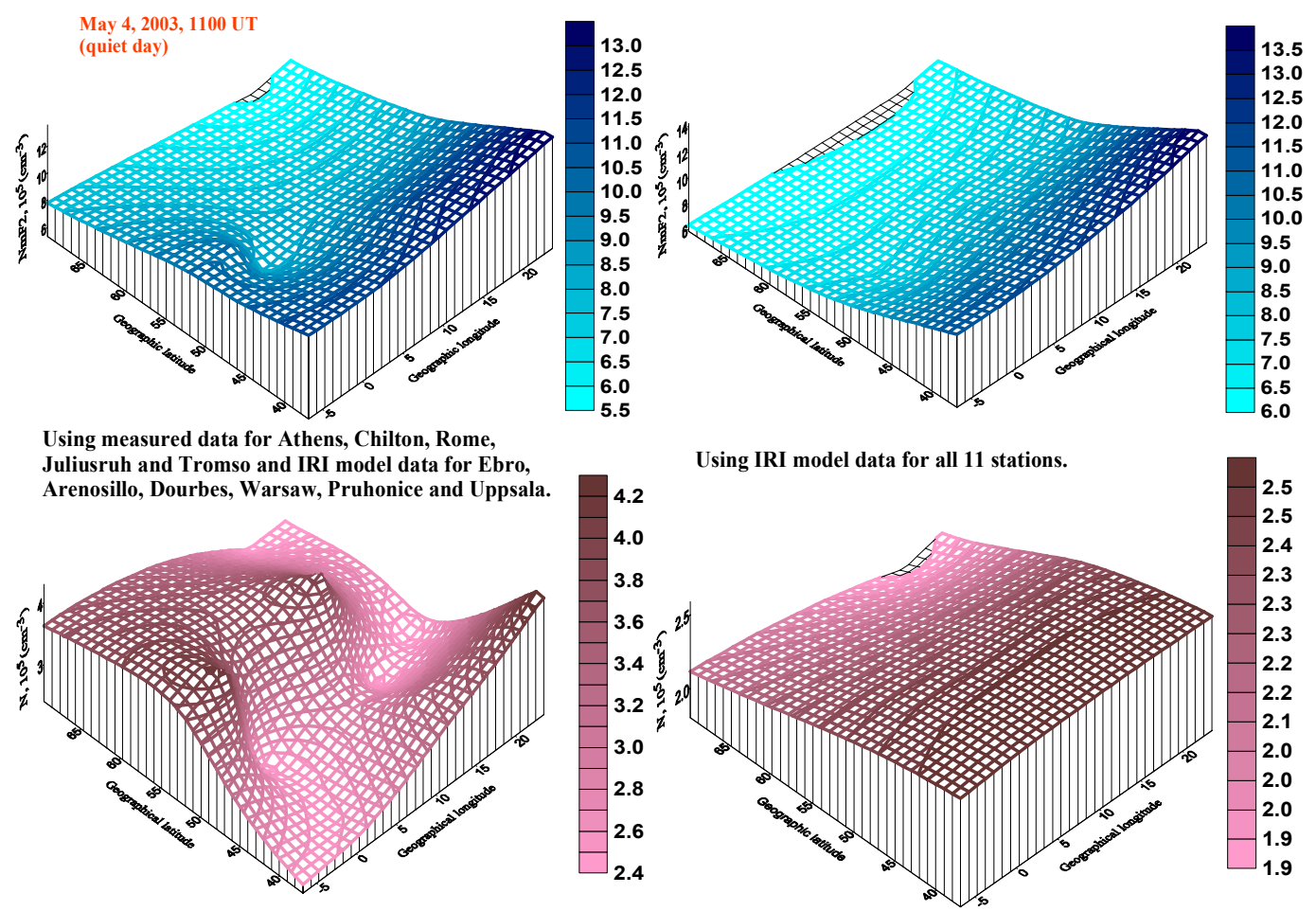

Fig. 4. Maps of the NmF2 and the electron density at $190 \mathrm{~km}$ values generated by measured data (left panel) for Athens, Roma, Chilton, Juliusruh and Troms $\varnothing$ and IRI data for Ebre, Arenosillo, Dourbes, Pruhonice, Warsaw and Uppsala on 4 May 2003 at 11:00 UT. Right panel represents the same ionospheric parameters calculated by IRI model for all selected stations.

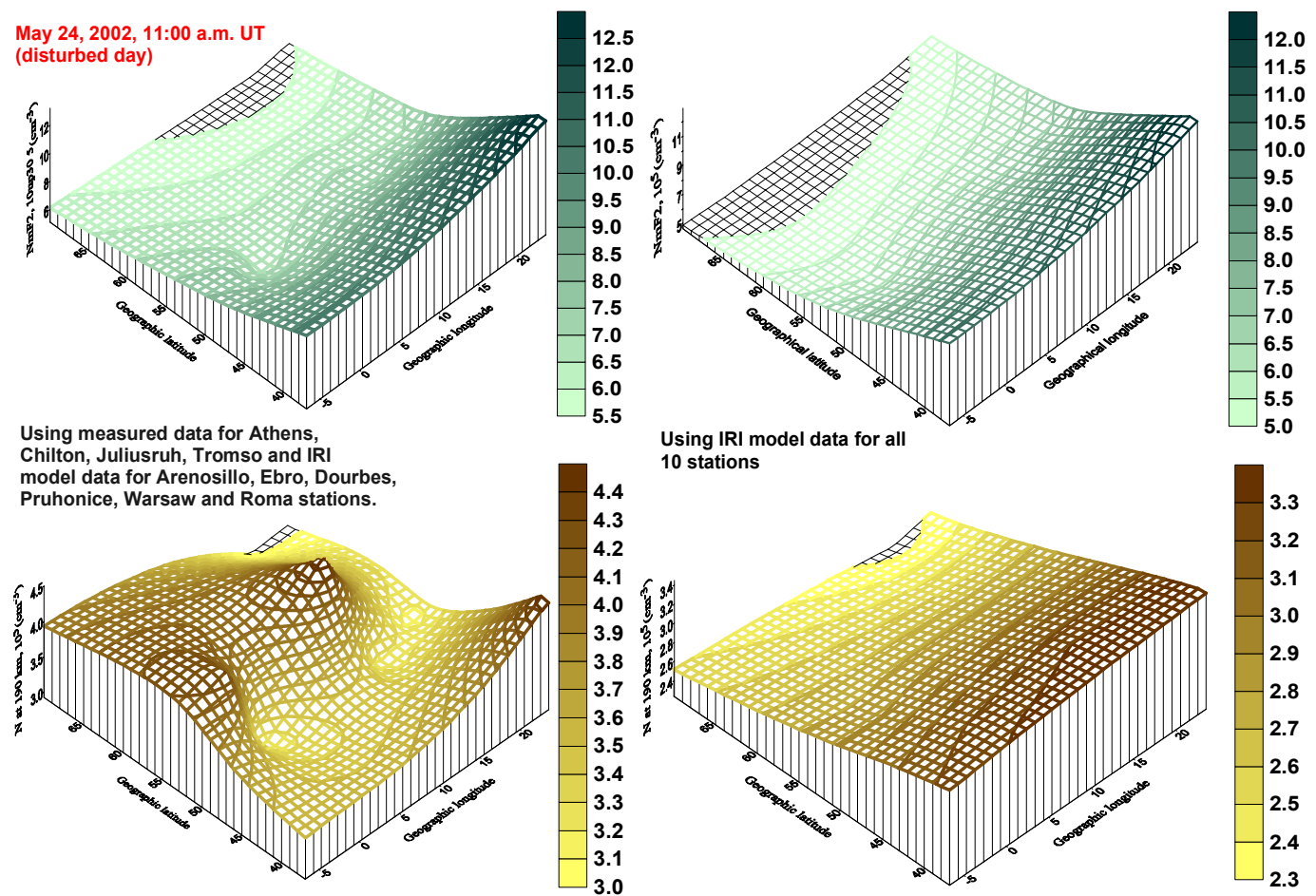

Fig. 5. Maps of the $\mathrm{NmF} 2$ and the electron density at $190 \mathrm{~km}$ values generated by measured data (left panel) for Athens, Chilton, Juliusruh and Tromso and IRI data for Ebre, Arenosillo, Dourbes, Pruhonice, Warsaw and Uppsala on 24 May 2002 at 11:00 UT. Right panel represents the same ionospheric parameters calculated by IRI model for all selected stations. 


\section{Conclusions}

It is widely accepted that the IRI model needs improvement for better representation of the F1-region electron density distribution over Europe under the both geomagnetically quiet and disturbed conditions. Some of the results of our comparative analysis presented in this paper show that updated IRI-2000 model with real-time ionosonde data over Europe describes the actual ionospheric structure better than the IRI model itself. It is particularly valid during geomagnetically disturbed periods. The quality of the updated maps, which makes resulting $\mathrm{N}(\mathrm{h})$ profile more realistic, will however depend on the number of ionospheric stations that can provide the real-time $\mathrm{N}(\mathrm{h})$ profiles (Zolesi et al., 2004).

Acknowledgements. We are grateful to the Grant Academy of the Academy of Sciences of the Czech Republic and to the Ministry of Education, Youth and Sports, which supported this work. Grants No. A3042101 and OC.271.10, respectively.

\section{References}

Araujo-Pradere, E. A., Fuller-Rowell, T. J., and Codrescu, M. V.: Storm: An empirical storm-time ionospheric correction model 1. Model description, Radio Science, 37, 5, Art. No. 070, 2002 a.

Araujo-Pradere, E. A. and Fuller-Rowell, T. J.: Storm: An empirical storm-time ionospheric correction model -2 . Validation, Radio Sciences, 37, 5, Art. No. 1071, 2002 b.

Bilitza, D.: International reference ionosphere 2002: Examples of improvements and new features, Adv. Space Res., 31, 3, 757767, 2003.

Bilitza, D.: International Reference Ionosphere 2000, Radio Science, 36, 2, 261-275, 2001.

Buresova, D., Lastovicka, J., Altadil, D., and Miro, G.: Daytime electron density at the F1-region in Europe during geomagnetic storms, Ann. Geophysicae, 20, 1007-1021, 2002.

Mikhailov, A. V. and Schlegel, K.: Geomagnetic storm effects at F1-layer heights from incoherent scatter observations, Ann. Geophysicae, 21, 583-596, 2003.

Zolesi, B. and Cander, Lj. R.: Effects of the Upper Atmosphere on Terrestrial and Earth-Space Communications, EE Conference Proceedings No. 491, 2, 565-568, 2003.

Zolesi, B., Belehaki, A., Tsagouri, I., and Cander, Lj. R.: Realtime updating of the Simplified Ionospheric Regional Model for operational applications, Radio Science, in press, 2004. 